\title{
HAROLD BLOOM Y LA CRÍTICA DE LA PERTINENCIA DE UN CANON
}

José María Espinasa*

\section{Harold Bloom y la crítica contemporánea}

El siglo veinte terminó marcado, en el terreno de la crítica literaria, por un libro muy ambicioso y necesariamente polémico, El canon occidental. Su autor, Harold Bloom, es todo un personaje, el único capaz de escribir un libro que la modernidad propondría como imposible, aquel que legislara sobre la jerarquía de valores de la historia literaria y estableciera una nómina para ese canon que formula el título. La coquetería de Bloom al agregar el matiz, tan gigantesco que deja de ser matiz, de occidental no impide sus ansias de absoluto, de erigirse en dios tonante de la percepción literaria en las próximas décadas o siglos. Dicho gesto es tan ambicioso que vale la pena intentar describirlo a partir de una personalidad de autor, una sicología en sentido amplio y -también- un sistema de poder literario anómalo en esas propias manifestaciones.

Bloom tiene una serie de virtudes fascinantes, aunque no siempre recomendables, por ejemplo: es el crítico que ha conseguido para sí un estatuto público de estrella de rock o figura del deporte. Sus libros se los disputan los editores, sus derechos se negocian en el gran mercado, y sus entrevistas son siempre noticia. ¿Qué otro crítico demanda

\footnotetext{
* Escritor.
} 
JOSÉ MARÍA ESPINASA

tanta atención de la prensa? Ninguno. A la vez sus textos son discutidos en los círculos académicos más exigentes, así sea para denostarlos ferozmente, pero no les pasan desapercibidos. Todas estas virtudes mercadotécnicas las consigue con armas del mismo nivel: declaraciones escandalosas y provocativas, personalidad de histrión en sus participaciones en público, sentencias inspiradas que se quieren indiscutibles y constantes debates con los otros críticos. No hay que lamentarse de que esto sea así, aunque tampoco hay que olvidarlo.

Por otro lado esa gesticulación se apoya en una evidente pasión, una enorme acumulación de lecturas que no quisiera calificar de eruditas, y una abundancia de propuestas literarias no siempre claras, articuladas en sistemas históricos bastante convincentes. Recuperó para nuestra deteriorada posmodernidad el sentido de la descripción histórica y la combinación de distintas fuentes de inspiración teóricas, del talmud a la psicología y de Nietzsche a la teoría de la incertidumbre. Su prepotencia, típica de un convencido 'hombre americano', roza lo sublime al mismo tiempo que lo ridículo. Sabe persistir en sus obsesiones -Wallace Stevens o Shakespeare- y validar sus lecturas en los propios textos, cosa que la crítica había dejado de hacer; ya no permitía leer 'un poema como un poema'. En efecto, Bloom recuperó para la crítica literaria su carácter literario.

Cuando el canon apareció -1995- las reacciones fueron inmediatas: gran éxito de ventas y condena unánime de los comentaristas. Poco a poco otras voces empezaron a expresar sus desacuerdos con mayor matiz y riqueza polémica. De antemano el Canon es un libro tan personal que nadie puede decir ‘estoy de acuerdo', es cómo decir “estoy de acuerdo con En busca del tiempo perdido o Los hermanos Karamazov”, no es el acuerdo el lugar de la lectura, pero tampoco el de la aceptación sino el de la discusión. La mayoría de los libros de Bloom, a pesar de su talante impositivo y su condición didáctica, son textos que invitan a la discusión, que la propician y la quieren. Ambivalentes y paradójicos son, por un lado, sumamente propositivos (véase La angustia de las influencias) y por otro instauran un corpus más obligatorio que indiscutible. 
Este tipo extraño hace, además, todo lo que no recomiendan las buenas maneras: no se adhiere a ningún sistema de análisis y más bien se pelea con todos, aunque los usa sin mala conciencia cuando los necesita. Pero tampoco propone un nuevo sistema de reflexión ni se apunta entre los que creen que no hay ninguno válido; no se arrepiente de su centralismo cultural -el inglés es la lengua dominante, Shakespeare la punta de la pirámide del Canon-y lo reivindica a cada rato. Para los académicos es un periodista, para los periodistas un académico y a él parece no importarle qué es, aunque es sintomático el orgullo cuando apela a sus grados universitarios tanto como a sus innumerables lectores.

Un elemento importante es que Bloom no pertenece a una tradición dominante de crítica norteamericana, ni a la influida por un complejo cientificista de origen anglosajón (y, a veces, germánico) ni a la urdimbre glosolálica de origen francés (hace de las distintas formas de la desconstrucción su bestia negra) mientras observa cómo las tendencias se pelean por atraerlo a sus filas. Me interesa destacar, porque es fuente de sus virtudes y evidencia de sus limitaciones, el poco cuidado que pone en dialogar con sus pares franceses, simplemente ignorándolos, pero copia ciertos comportamientos - por ejemplo, de Roland Barthesen la seguridad de su lugar público y en lo que los medios esperan de él. Nunca decepciona a sus lectores ni a sus adversarios. Todo su éxito en el dispositivo literario que desarrolla depende de un innegable talento para aventurar (y uso la palabra expresamente) hipótesis sugerentes.

Aunque su obra ensayística empieza a finales de los años cincuenta es hasta la década de los setenta que aparece como un caso excepcional, especialmente en La angustia de las influencias, libro de una enorme riqueza en sus propuestas, extraño en la forma discursiva y a veces confuso en sus conclusiones. Se ha subrayado, sobre todo a partir de su aparición, el poder epigramático del discurso de Bloom, sus divagaciones concluyen de pronto en aforismos deslumbrantes que hay que valorar una y otra vez, pero que no pierden su poder magnético ni agotan su capacidad de sugerencia. La teoría de las influencias pone sobre la mesa una discusión muy importante: el diálogo con los muer- 
JOSÉ MARÍA ESPINASA

tos, tan propio del romanticismo, movimiento estético en el que hay que ubicarlo, y sobre el que volveremos.

Una época, como es la nuestra, que reivindica sobre todo la capacidad de elección del lector (y creo que no hay que renunciar a ello) mira con desconfianza la elaboración de un canon, aunque éste sea obvio. No hay muchas razones ni tiene sentido -salvo ciertos tristes chauvinismos- discutir si Shakespeare es mejor que Cervantes y a su vez si este es mejor que Goethe o Molière. En un libro posterior al Canon, Cómo leer y por qué, Bloom escribe una posdata en plan didáctico, más clara pero con menos poder intuitivo, preocupado por algo que ya no es sólo una fantasmal amenaza que permite plañir sino una realidad evidente: no la muerte de la literatura sino la muerte del lector. Así el canon es ante todo una necesidad de poner orden, aunque luego se lo destruya, ya que la literatura ha llegado a un grado peligroso de catatonia, en la que no se comunica con sus lectores, con el beneplácito de las estructuras de poder, a las que no les importaría que ya no se leyera, lo que facilitaría olvidar lo que una sociedad que puso en su centro la lectura tuvo de bueno.

Lo que se desprende del conjunto de sus libros es la enorme preocupación por definir la tradición, ésa que los románticos pusieron en tela de juicio y revisaron de una manera muy profunda, pero que a la vez volvieron volátil, endeble, casi etérea, casi inexistente ya que no hay obras dignas de ser incluidas en ella. Bloom es un tipo de lector que se quiere abarcador y omnicomprensivo, se entusiasma por igual con Walt Whitman y Emily Dickinson, no toma partido antes de leer sino después, y esa proposición ya no es militante en las particularidades sino en la organización del conjunto. Necesita volver discurso ese libro que según algunas religiones y Jorge Luis Borges escribimos entre todos. Bloom piensa, y creo que tiene razón, que si no se realiza ahora la labor de rescate de lo más esencial que tiene la literatura se habrá perdido para siempre, la humanidad habrá sido despojada de su corazón sin que esto le traiga la muerte, la comunicación se convertirá no sólo en un fenómeno trivial -intercambio de datos- sino en un monstruo. 
Bloom traza su genealogía entres los ‘críticos fuertes’ y muestra su admiración por Emerson. Así la desaparición de esa tradición traería un desastre, la desaparición no del escritor sino del crítico, y por lo tanto volvería vacua la actividad del amanuense. Obras como El Canon y similares hacen de la historia literaria una novela, emocionante por cierto, en la que los personajes son obras y estilos. Pero al devolverle la dignidad a la historia literaria la transforma en obra de ficción, cosa que hay que agradecer, permite el ejercicio de la imaginación con igual libertad que en los otros géneros, y reivindica -cómo podría ser de otra manera- la crítica como creación. Esas miradas globales sobre la literatura permiten saber más que dónde estamos situados dónde nos situaríamos si se pudiera escoger un lugar. La novela familiar que, a través de Freud, Bloom hace patente en cualquier relación del 'efebo' (amante, hijo o heredero) con su precursor está presente también en lo literario. En cierta manera todo gran poeta moderno siente la necesidad de escribir ese retrato familiar; un ejemplo claro (y brillante) es el de Los hijos del limo de Octavio Paz.

Se trata de un árbol genealógico, la búsqueda de transparencia en el linaje de quien escribe, la búsqueda de identidad en ese diálogo con los muertos. Una manera de hacerlos presentes, de saber que viven en ese diálogo, de encontrar el propio rostro en el rostro de esos otros, que lo son-otros-de otra manera que los de verdad diferentes; propone la familiaridad como una mediación ante la alteridad. Una de las claves metodológicas, si las hubiera, en Bloom es que, tal como hace con Freud, lee todo como literatura, no -como hace por ejemplo la crítica francesa- como filosofía. Por eso los que lo acusan de ser un crítico sentimental no se dan cuenta que indirectamente aciertan, ya que su trabajo como escritor está ligado al deseo, al poder del deseo. Es por eso, también, que sus largas reflexiones históricas desembocan casi siempre en enunciados no históricos (esa capacidad epigramática que se mencionó antes), incómodos cuando no molestos para la investigación académica y pasto seco para la hoguera de la feria de vanidades de la literatura estadounidense. 
JOSÉ MARÍA ESPINASA

La importancia de Bloom reside, como crítico, en que la suma de características personales -lo que llamaríamos un estilo- sirve para poner el dedo en la llaga de la literatura contemporánea: después de Shakespeare -a partir de Cervantes- la literatura occidental es por un lado un admirable corpus de textos, cuya conversación a través del tiempo - de la historia- es una más de sus creaciones, pero que -más allá de la fascinación que provocan- están lejos de ese período que Bloom llama la edad teocrática, que incluye a los griegos, a los romanos, e incluso a Dante y a Shakespeare (aunque Bloom los coloca en el siguiente período) y, desde luego, a toda obra literaria no occidental. A partir de entonces la literatura se precipita en busca de su desaparición, lo que significa la desaparición del lector. Y las causas de ese autismo están en el descubrimiento de la grieta emersoniana en la reacción divina: la huella de esa grieta es la literatura o, si se quiere, en forma global, el arte.

Busquemos causantes -aunque no culpables. Una hipótesis, que no le molestaría a Bloom, es pensar que después de Shakespeare la literatura es prescindible, ya no es necesaria. Otra, con más miga, es que al perder totalmente su vinculación con el gesto creador, al ya no tener ni siquiera un rescoldo de su vocación sagrada, puso en evidencia a Dios como vacío al volverse profana. Esa es la hazaña de Cervantes en El Quijote: poder escribir por fin liberado de cualquier obligación teocrática, ni siquiera litúrgica, recogiendo el gesto del Decameron o de los Cuentos de Canterbury. Al escribir una obra plenamente humana Cervantes dejó de hablarle a los hombres, al precipitarse en lo profano se quedó no sin Dios sino sin interlocutores. No de golpe, desde luego, pero es Cervantes quien habla a través de la pluma de Samuel Beckett. Y no es que Bloom se alarme ante esta situación, simplemente la constata al construir su discurso crítico.

Tal vez por eso resulte tan importante en su discurso la literatura norteamericana, ya que es la única que se puede situar después de Shakespeare pero antes de Cervantes, en un lapso donde aún es posible rescatar su sentido. El verdadero problema surge, sin embargo, con el romanticismo, movimiento que reconoce el vacío y que, además, 
se complace en él y lo reivindica, se vuelve conciente de esa grieta de la creación por la que se cuela el significado. Por eso el avance en el tiempo -en la historia- se da para Bloom como un relevo de interpretaciones erróneas o desviadas de los herederos a sus precursores. Al fin y al cabo al reducir su espectro de recepción al efebo Bloom sabe que la muerte del lector es la muerte del escritor ya que se escribe para otro escritor. Por eso la poesía se vuelve una ‘mercancía’ refractaria al mercado, un producto no comercializable, una no-mercancía. El poeta moderno es ante todo lector, y no para entender sino para prolongar, mientras que el poder como aparato lo que quiere es que se desentienda, que se olvide del diálogo con los muertos.

La lucha entonces no se da en el terreno de la poesía, aunque es allí donde Bloom la describe, sino en el terreno de la narrativa. Narrar -más estrictamente: novelar- es la gran virtud de los modernos, pero el veneno que los corroe. Eso se nota, por ejemplo, en la manera en que Bloom da por sentado que el lector conoce la novela familiar de la crítica, y su discurso se transforma en una sobremesa entre contertulios bien enterados de todos los guiños, ligados por un nexo que no está -ni estará nunca- en discusión. Me sorprende que no busque vincular lo que le sucede a la literatura con la aparición de la imprenta, ya que la coincidencia en el tiempo no puede ser casualidad y es evidente que la grieta se materializa en paralelo al crecimiento del invento de Gutenberg. La literatura se aisló en sí misma al ser privada de su catacumba gracias a la democratización que impulsó la imprenta.

Si se es capaz de ver sin tanto prejuicio la Edad media nos daremos cuenta que en ese lapso la literatura tenía un elemento colectivo -no necesariamente popular, aunque a veces sí- que después le está prohibido. Al ser la literatura el gesto de un individuo mientras que la lectura aún pertenecía a la colectividad, el escritor buscó equilibrar la ecuación no devolviendo lo primero a la colectividad sino quitándole a ella lo segundo. ¿A quién le habla Bloom en sus ensayos? Más allá de su éxito ante el público creo que es evidente que le habla a otros críticos. La angustia de las influencias sigue siendo su libro más propositivo y el más difícil justamente porque aún no tiene las características didác- 
JOSÉ MARÍA ESPINASA

ticas que adquirirá después. Dicho de otra manera, la literatura ya no se escribe -ni se representa, si pensamos en Shakespeare- sino que se imprime. Esa multiplicación permite que la página se le aparezca al escritor como espacio de lucha, como patria. De allí a la página en blanco de Mallarmé, que se prolonga en el escenario en blanco de Beckett, no hay sino un paso.

La estructura interpretativa de la que parte Bloom tiene entonces dos perspectivas, dos maneras de proseguir adelante en busca de un futuro para la literatura: por un lado el regreso a la meditación sobre los grandes libros, los grandes autores -y me refiero a Homero y al Yavhista- y por otro a la introspección psicológica del acto de escribir, a Freud y todas sus derivaciones teóricas, fallidas o no (hay que señalar que es Lacan uno de los pocos franceses de los que no abomina). La importancia de Freud para Bloom es patente a lo largo de todos sus libros, lo cite expresamente o no, junto a -pero muy por encima de ellos- Nietzsche y Emerson.

\section{Harold Bloom y los textos religiosos}

Más que una esquizofrenia -siempre posible-el interés de Bloom por las doctrinas religiosas y por el papel de la religión en el final de milenio es a la vez sintomático de la época y representativo de una actitud. No existe en una crítica tradicional literaria ese interés en los textos religiosos como símbolo ya que sólo pueden ser descritos como obra literaria. En esa dirección lo significativo en Bloom es que lo hace desde su origen judío y desde su pertenencia a una cultura, la norteamericana, que no puede pensar el mundo sin volverlo un asunto religioso. Creo que por ahí, más que por sus profundos desacuerdos metodológicos, va su distancia con la crítica literaria francesa, pues ésta sí capaz de ignorar el espacio del texto sagrado, ejerciéndose como oficio laico.

Por eso también la propuesta y necesidad de un canon, ya que se necesitan organigramas, jerarquías, santorales. Bloom observa con escepticismo pero con fascinación las necesidades religiosas seudo místicas 
de una nueva época y aprovecha su trivialidad para describir la narración que hay detrás de la lucha entre doctrinas. En cierta forma decide hacer una narratología de la mística aprovechando su cualidad de texto, por lo tanto de corpus interpretable. Por eso también su enorme admiración por Freud e, indirectamente, por Shakespeare, a quien sitúa como texto sagrado de una época laica. Al menos lo intenta, y no está de más pensar en que sólo la obra del dramaturgo inglés puede ocupar el lugar de un texto fundador en nuestra cultura, de la manera que lo hizo Homero en la griega, y no la Biblia en la judeocristiana.

No hay que abandonar el vacío creado por nuestro escepticismo a los profetas de lo trivial en una 'nueva era’ más condicionada por el comercio que por una necesidad profunda de restaurar lo divino. No, de los trabajos de Bloom se desprende una exigencia terrible: ese vacío debe permanecer como vacío y sólo aparecer como un eco en la literatura. Hay que defender las ruinas de la religión en tanto tales: ruinas. Si su propuesta metodológica fue poder volver a leer un poema como poema hay que hacer extensiva esta exigencia en otros niveles, con una ligera pero importante variante: todo hay que leerlo como un poema. Es decir, despojado de su sentido religioso. No creo que él aceptara esta lectura que hago de su obra, pero me parece evidente. Incluso su visceral rechazo de ciertos teóricos, como el caso de Jacques Lacan, se debe a que reproducen una lectura esotérica del texto, de cualquier texto. Reproducen la especialización -el universo de los elegidos-sin restaurar su espíritu religioso. Bloom las ve como sectas vacías de sentido, sólo operativas en el nivel de la estrategia del discurso.

Por eso un libro como su estudio sobre la angelología está todo el tiempo a punto de irse por un lado iconográfico, no textual, pero siempre resistiendo la tentación en nombre de ese texto implícito en el origen de su escritura. Es llamativo también que sea un libro mucho más descriptivo, es decir, menos militante, que sus ensayos estrictamente literarios. Bloom describe el proceso discursivo de lo religioso, y si bien señala y juzga constantemente, no pontifica, no establece canon alguno. Observa la religión como una historia sin ser un historiador, sino más bien, como ya se dijo, un novelista. Esta mirada narrativa 
JOSÉ MARÍA ESPINASA

deudora de la historia sí es común a todos sus libros: entiende la literatura como un intercambio, un entretejido, y por eso uno de sus mejores textos, aun no lo suficientemente estudiado, es La angustia de las influencias. Bloom entiende la literatura como un crisol en evolución, en donde todo autor es todo autor anterior, sobre todo si se trata de poetas fuertes, es decir aquellos que reciben mejor ese pasado, esa influencia. Pero la historia no es para Bloom, como pensó Marx, que cometió el mismo error que Freud con los sueños, una ciencia sino una obra de creación.

Saber si tiene, lo cual es probable, mucha influencia de la idea cabalística del mundo como un libro que entre todos se escribe, no importa mucho, lo que importa es que ese ‘entre todos' es un autor que hay que tomar en serio. Pero ese canon o cualquier otro no representa un nosotros, no representa tampoco una razón histórica, y Bloom, haciendo alarde de un autoritarismo que lo concede su calidad de 'maestro pensador' en el peor sentido en que los franceses utilizaron esta expresión en los años ochenta, o como una 'cabeza parlante' tomando la expresión prestada al conocido grupo de rock, Bloom acaba por rehuir la discusión que tenía en su manos, la que era de veras importante sobre el papel de la crítica como creación. 